\title{
EXPERIENCE WITH IMAGING BY USING OF MICROFOCUS X-RAY SOURCE
}

\author{
Zdenko Zápražný ${ }^{*}$ — Dušan Korytár ${ }^{*}$ — František Dubecký ${ }^{*}$ - \\ Vladimír Áč ${ }^{* *}$ Z Zbigniew Stachura ${ }^{* * *}$ - Janusz Lekki ${ }^{* * *}$ \\ — Jakub Bielicky ${ }^{* * *}$ — Ján Mudron̆ ${ }^{* * * *}$
}

\begin{abstract}
In this paper we present the current work and experience with using microfocus x-ray generator and commercial CCD camera for $\mathrm{x}$ - ray imaging purpose. There is a need in laboratories for the development of imaging methods approaching synchrotron radiation sources, where the brilliance of radiation is on very high-level. Generally, there is no continuous access to synchrotron facilities. Several synchrotron radiation laboratories allocate the access via a proposal system. Thus the time for synchrotron radiation experiments seldom exceeds more than 1-2 weeks per year, which restricts its application to a few selected experiments. Even in future, the routine characterization of samples will be performed mainly at the experimenters home laboratories [10]. In this contribution we show that with the present set-up it is possible to achieve the spatial resolution down to $\mu \mathrm{m}$ and with the appropriate geometry a phase contrast images are observable.
\end{abstract}

K e y w or d s: x-ray imaging, x-ray imaging system, parameters of the x-ray imaging system

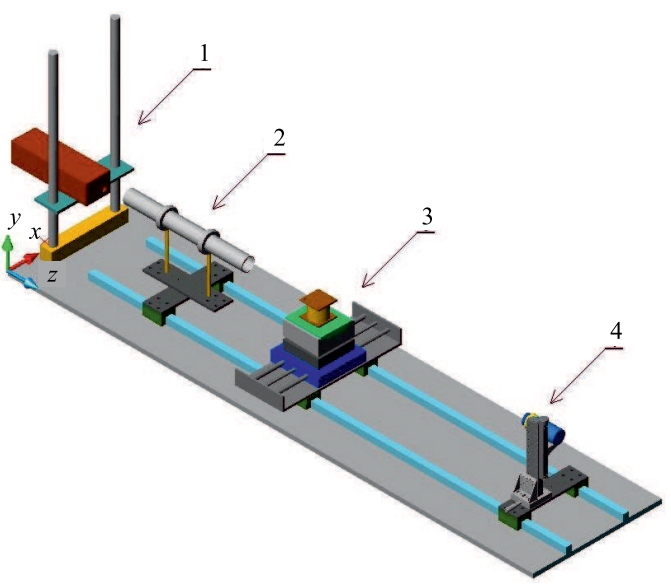

Fig. 1. Experimental setup (1) Hamamatsu microfocus, x-ray source (L6731-01 type), (2) Collimator $\varnothing 50 \times 500 \mathrm{~mm}$ (option), (3) Newport goniometer to adjust and rotate the object or optics (resolution $\left.0.0002^{\circ}\right),(4)$ x-ray Mini FDI camera, Photonic Science with pixel resolution: $1392 \times 1040$ (4:3 aspect ratio), input pixel size: $6.4 \mu \mathrm{m}^{2}$, input active area: $10 \times 8 \mathrm{~mm}$, Scintillator: gadolinium oxysulphide doped with terbium and energy response: optimum $5 \mathrm{keV}$ to $17 \mathrm{keV}[9]$.

\section{INTRODUCTION}

Recent developments of the x-ray imaging techniques at synchrotrons such as phase contrast imaging [1,2] present a strong driving force for the development of laboratory x-ray imaging techniques [3]. The brilliance of new micro-focus sources combined with suitable source-side optics gives the possibility to transfer some demanding experiments from synchrotrons to laboratories. Concerning the detection side, new approaches include single photon counting with semiconductor radiation detectors and the so called "colour imaging allowing evaluation in a preselected photon energy window [4]. These new techniques substantially improve the overall diagnostic performance of new generation x-ray systems [5].

\section{EXPERIMENTAL SETUP}

Based on our experience in x-ray crystal optics, semiconductor detectors and x-ray imaging, we are developing a variable x-ray optical bench to study some of these modern imaging techniques [5].The enclosed radiation leak protected optical bench $2.6 \mathrm{~m}$ long contains a vertical stand for a Hamamatsu microfocus x-ray source (L673101 type) with declared focus size $8 \mu \mathrm{m}$, target voltage: 20-80 kV, target current: $0-100 \mu \mathrm{A}$, minimum distance focus-object: $12 \mathrm{~mm}$, beam angle: $39^{\circ}$, environmental $\mathrm{x}$ ray dose leakage: $5 \times 10^{-3} \mathrm{mSv} / \mathrm{h} \max$, longitudinal slides for changing geometrical magnification and moving various components, a Newport goniometer to adjust and rotate the object or optics, and another stand for detector or camera slides $[6,8]$.

\section{THEORY}

The first results have been obtained by using the technique of free-space propagation imaging.

\footnotetext{
* Institute of Electrical Engineering, SAS, Vrbovská cesta 102, 92101 Piešt’any, zdenko.zaprazny@savba.sk; ${ }^{* *}$ Alexander Dubček University of Trenčín, Študentská 1, 91150 Trenčín, Slovakia, vac@tnuni.sk; *** Institute of Nuclear Physics, Polish Academy of Sciences, ul. Radzikowskiego, 31-342 Krakow, Poland; ${ }^{* * *}$ Magic Trading Corporation, a.s. 03101 Liptovský Mikuláš, Slovakia
} 


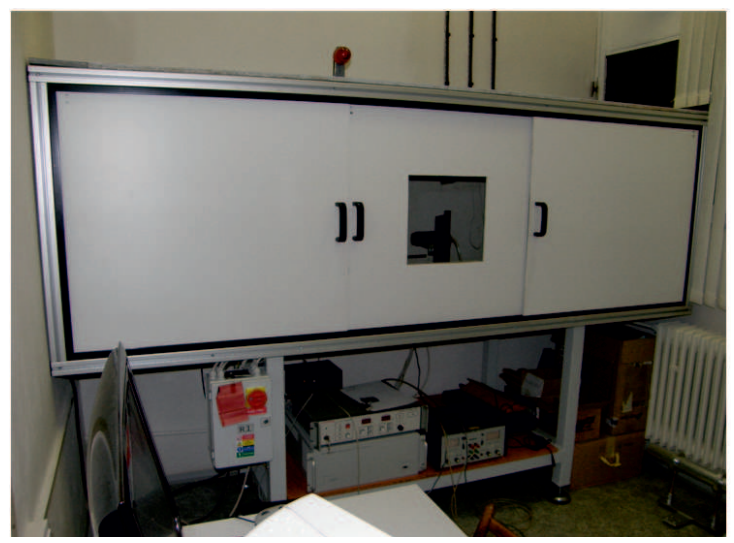

Fig. 2. The enclosed radiation leak protected bench top x-ray imaging system

\begin{tabular}{|c|c|c|c|}
\hline 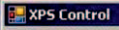 & & & $-[0]$ \\
\hline Slage moving & functions - & & \\
\hline Start & Get & Move relative & $c$ Gon \\
\hline \begin{tabular}{|l} 
IP_Address: \\
147.213 .232
\end{tabular} & $\overline{23} \stackrel{\text { Port }}{\Gamma} \Gamma_{5001}^{\text {Tim }} \Gamma$ & 1: Displocement [deg) Move absolute & \\
\hline Manochromato & & & \\
\hline close & Peltier START & 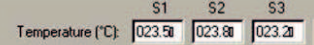 & \\
\hline & Fan START & Resistance $( 0 \mathrm { hm } ) \sqrt { 1 1 5 . 9 0 } \longdiv { 1 1 6 . 0 0 } \longdiv { 1 1 5 . 8 0 }$ & $\begin{array}{l}\text { Lyce } \\
\text { START } \\
\end{array}$ \\
\hline$-x$ detector & & & \\
\hline Complevel \%: & 50 Count time & ${ }_{100}$ Count Stat \60 cycle & Result \\
\hline Ouput file nan & 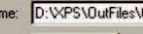 & - Enegylevel & \\
\hline & Open file & $\checkmark$ Energy scan & \\
\hline Step dives - & olward Back. & $」$ Diver: $\longdiv { 2 }$ Sleps: $\overline{10}$ Delay: & 10 \\
\hline 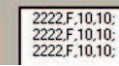 & & 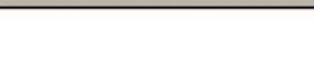 & $\exists$ \\
\hline
\end{tabular}

Fig. 4. The self developed software screen for control of several function like goniometer, tilt, monochromator, x-ray detector, stepper motor, which can be extended to other required functions

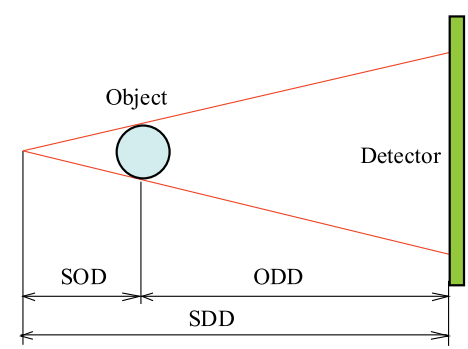

Fig. 5. Geometry of the so called Free Space Propagation Imaging. SOD-Source Object Distance, ODD-Object Detector Distance, SDD-Source Detector Distance

In order to achieve phase-contrast imaging, the x-ray tube must provide a sufficient degree of spatial or lateral coherence which is given by

$$
d=[\lambda(\mathrm{SOD})] / f,
$$

where $\lambda$ is the wavelength, SOD is distance between the source and the object an $f$ is the focal spot size of the tube. The magnification that occurs at a distance ODD is given by the relation

$$
M=(\mathrm{SOD}+\mathrm{ODD}) / \mathrm{SOD}=\mathrm{SDD} / \mathrm{SOD},
$$

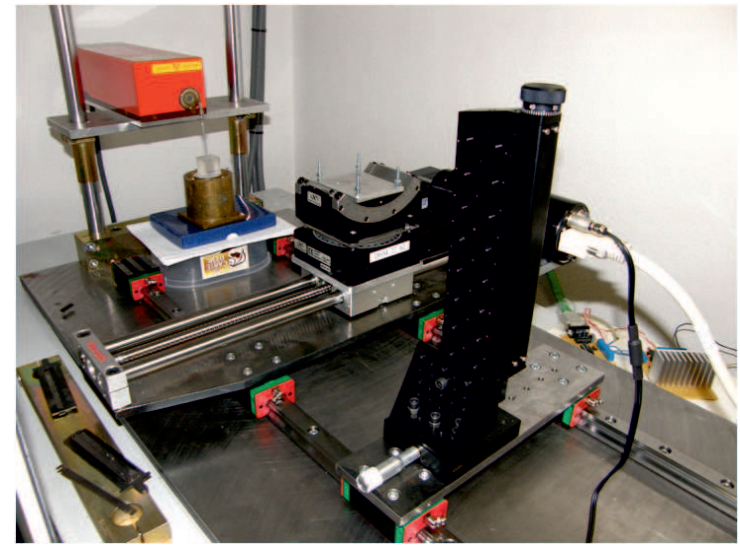

Fig. 3. Interior of the x-ray imaging system with x-ray source (red box), Newport goniometer in the middle and CCD camera the black stand in the right of the picture

The image contrast obtained from the x-ray intensity profiles of an object is provided by the relation

$$
\text { Contrast }=\left(I_{\max }-I_{\min }\right) /\left(I_{\max }+I_{\min }\right),
$$

Another parameter that can be calculated in the image is the penumbra arising form the finite size of the focal spot in the magnification images. From simple geometry, the geometrical unsharpness is

$$
U_{g}=f(\mathrm{SDD} / \mathrm{SOD}) .
$$

Where SDD is the distance between the source and the object, SOD is the distance between the object and the detector and $f$ is the focal spot size [2].

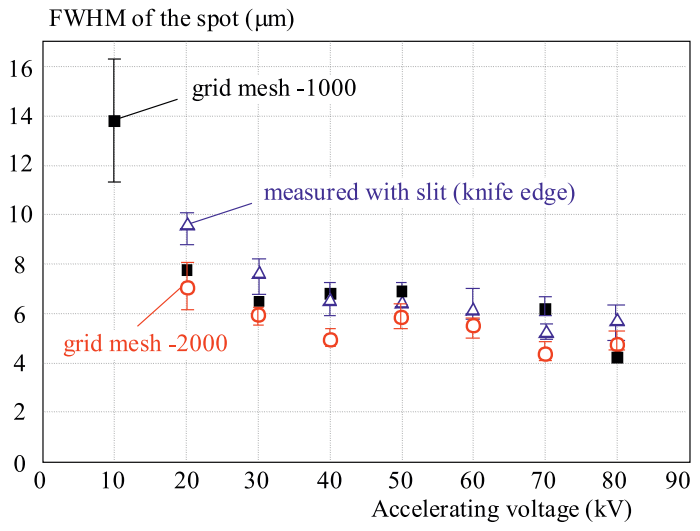

Fig. 6. Dependence of the spot FWHM on the accelerating voltage

\section{RESULTS}

\section{Testing of focus size of x-ray source}

The focus size of the x-ray source with a transmission tungsten anode (declared as of $8 \mu \mathrm{m}$ ) has been measured using the technique of imaging a tungsten crossed wires according to EN 12543-3 [7]. At the full power of $80 \mathrm{kV}$ and $100 \mu \mathrm{A}$ the technique has given focus size of $8.6 \mu \mathrm{m}$ in horizontal and $6.2 \mu \mathrm{m}$ in vertical direction [5]. 


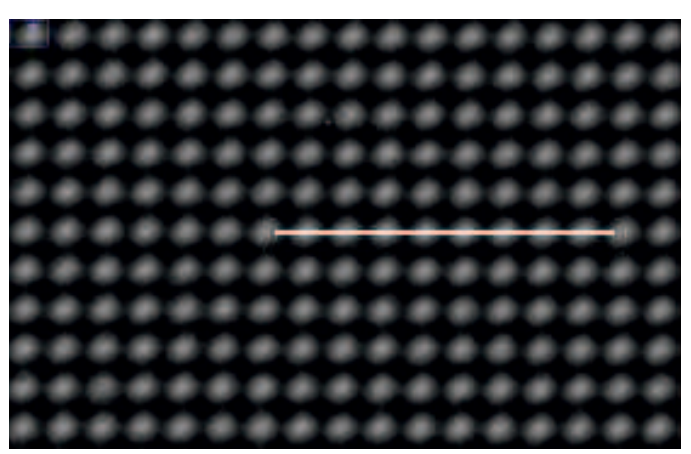

Fig. 7. x-ray image of a gold microscopic grid with 4 to $5 \mu \mathrm{m}$ stripes, $12.5 \mu \mathrm{m}$ period taken with the geometrical magnification of 9.1 , accelerating voltage $40 \mathrm{kV}$, current $100 \mu \mathrm{A}$, exposure time $10 \mathrm{~s}$

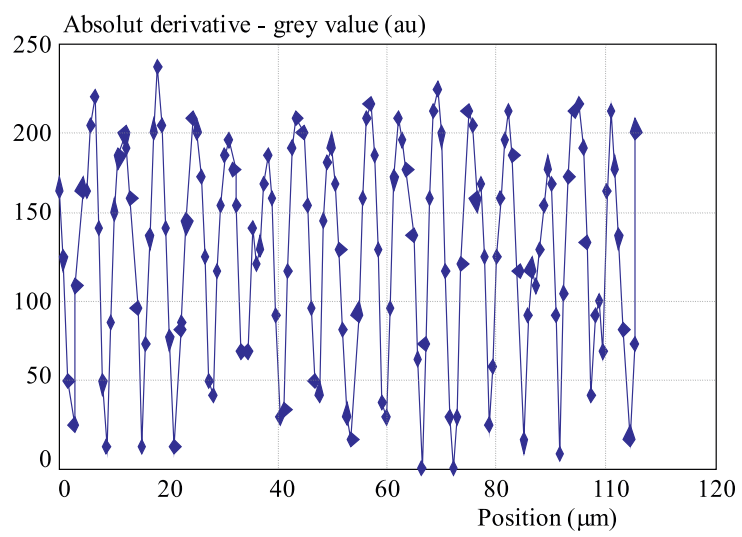

Fig. 9. Absolute value of the first derivative of the transmitted intensity profile and calculated FWHM of 3-5.2 $\mu \mathrm{m}$

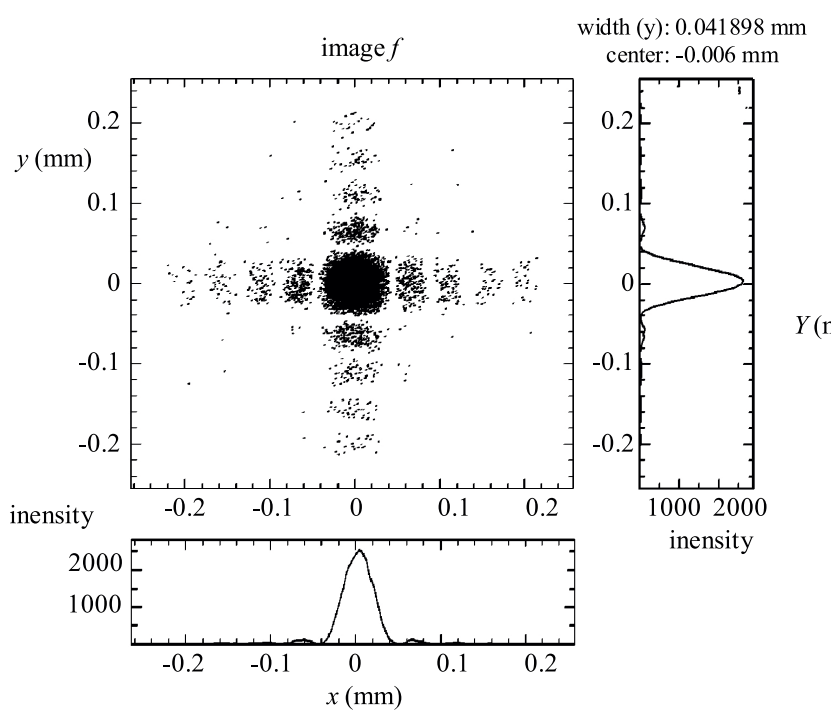

Fig. 10. Fraunhofer diffraction at a rectangular slit as simulated by the ray-tracing program RAY

\section{Dependence of x-ray tube focus size (FWHM) on tube voltage}

The measurements were performed with three tools: grid mesh-1000, grid mesh-2000 and a slit, edges of which were used as "knife edges. Though differences are larger

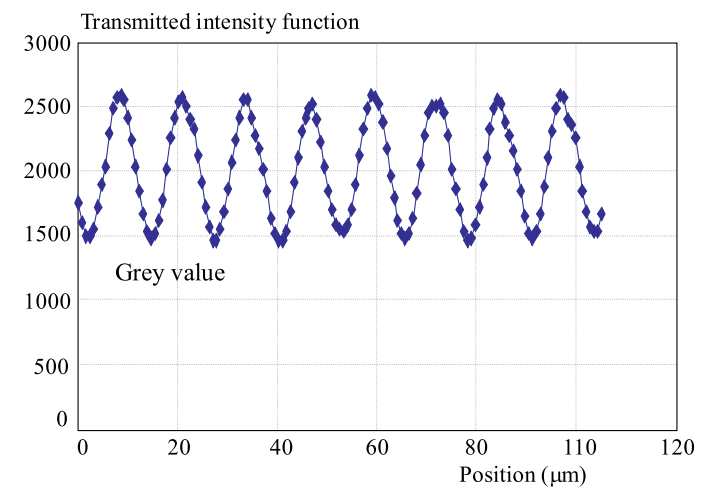

Fig. 8. Transmitted intensity function from the white horizontal region indicated in Fig. 7

than estimated error bars, the results seem to be consistent between the three sets.

\section{Measurement of spatial resolution}

One of the most important imaging parameters is spatial resolution. A technique using the full width at half maximum (FWHM) of the absolute derivative of the transmission function of a gold grid has been used for the purpose. The distance between the source and the sample was $27 \mathrm{~mm}$ and the distance between sample and camera $219 \mathrm{~mm}$, while the magnification was 9.1.

\section{Simulation of Fraunhofer diffraction}

To assess the coherence character of imaging, we are simulating the Fraunhofer diffraction at a rectangular aperture using the BESSY ray-tracing program RAY [9]. Preliminary results show that ripples up to $100 \mu \mathrm{m}$ distance from the edges are observable (see Fig. 10), confirming beam coherence. The simulation parameters: number of rays: 10000000 , source: $(\mathrm{w} \times \mathrm{h} \times \mathrm{d})=0.008 \times$ $0.008 \times 0.008 \mu \mathrm{m}$, photons energy: $\mathrm{E} 0=8039.960 \mathrm{eV}$, $(\lambda=0.1542 \mu \mathrm{m}), \Delta \mathrm{E}=4000-12000 \mathrm{eV}$. One optical element: slit $(\mathrm{w} \times \mathrm{h})=0.001 \times 0.001 \mathrm{~mm}$, source-slit distance: $32 \mathrm{~mm}$, slit-image plane distance: $290.8 \mathrm{~mm}$.

\section{The first images done with the built-up imaging system}

a) $M=1.02, \mathrm{SDD}=508.8 \mathrm{~mm}, \mathrm{SOD}=500 \mathrm{~mm} \mathrm{~b})$ $M=2.29, \quad \mathrm{SDD}=370.8 \mathrm{~mm}, \mathrm{SOD}=162 \mathrm{~mm} \mathrm{c}) M=$ $9.09 \mathrm{SDD}=290.8 \mathrm{~mm}, \mathrm{SOD}=32 \mathrm{~mm} 80 \mathrm{kV}$, current $100 \mu \mathrm{A}$, exposure time $20 \mathrm{~s}$. a) the absorption contrast is dominating, b) phase contrast is starting to be seen, c) phase contrast is quite good observable, brightness on the edges (minimum of intensity profile) due to the tilt of the beam in place with the change of the refractive index. $\mathrm{M}$ - geometrical magnification ( $\mathrm{M}=\mathrm{SDD} / \mathrm{SOD})$, SDD - source-detector distance, SOD — source-object distance. 


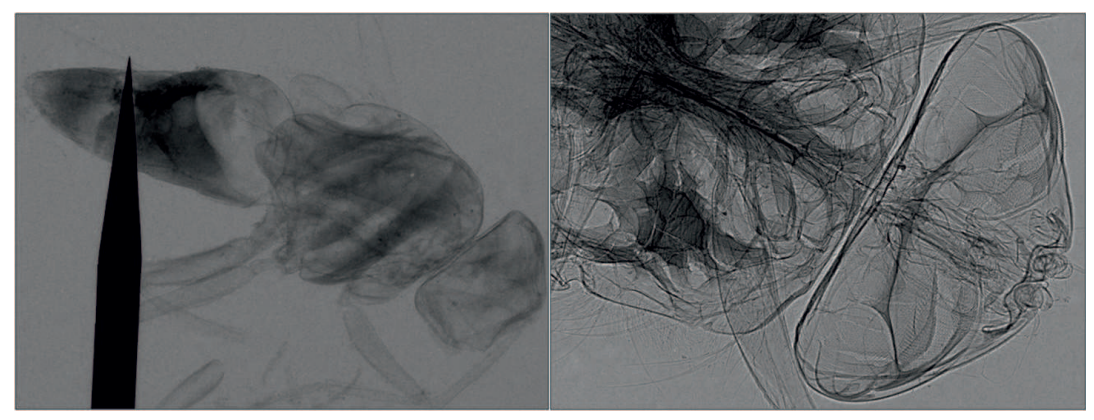

(a)

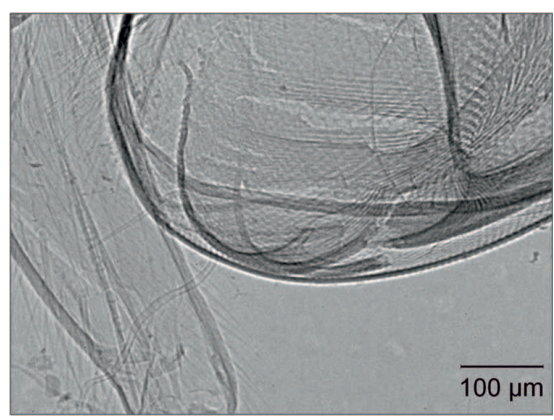

(c)

Fig. 11. The first images done with the built-up imaging system: (a) $-M=1.02 \mathrm{SDD}=508.8 \mathrm{~mm} \mathrm{SOD}=500 \mathrm{~mm}$, (b) $-M=2.29 \mathrm{SDD}$ $=370.8 \mathrm{~mm}$ SOD $=162 \mathrm{~mm},(\mathrm{c})-M=9.09 \mathrm{SDD}=290.8 \mathrm{~mm} \mathrm{SOD}=32 \mathrm{~mm}$

\section{CONCLUSION}

Basic parameters and options of the current set-up of the imaging system were defined. The first experience shows that with the present set-up it is possible to achieve the spatial resolution down to $3 \mu \mathrm{m}$. The system in this establishment is suitable for small samples, because of using a camera with a relatively small input active area approximately $10 \mathrm{~mm} \times 8 \mathrm{~mm}$. The high resolution rotation stage for the sample holder allowed us to take sequential computer tomography pictures which are now being reconstructed into $3 \mathrm{D}$ tomographs.

\section{Acknowledgement}

This work was financially supported by grant of Science and Technology Assistance Agency no. APVV- 045906, APVV-99-P06305 and Scientific Grant Agency of the Ministry of Education of Slovak Republic and the Slovak Academy of Sciences No. VEGA- 2/0153/10 and 2/0192/10 and COST Action MP0601.

\section{REFERENCES}

[1] CLOEtens, P. et al : J. Phys. D: Appl. Phys. 32 (1999), A145.

[2] GUNDOGDU, O. et al: Applied Radiation and Isotopes 65 (2007), 1337-1344.

[3] BARUCHEL, J.et al : J. Synchrotron Rad. 7 (2000), 196.

[4] DAVIS, T. J. et al : Nature 373 (1995), 595.

[5] ZAŤKO, B. et al : Nucl. Instr. And Meth. In Phys. Res. A 607 (2009), 67.

[6] KORYTÁR, D.-VAGOVIČ, P.-DUBECKÝ, F.-BOHÁČEK, P. : Basic Parameters of a High Resolution x-Ray System with a Microfocus Soruce, Biennial report 2007-2008, Institute of Electrical Engineering, Slovak Academy of Sciences.

[7] KORYTÁR, D.-DUBECKÝ, F.-ZAŤKO, B.-VAGOVIČ,

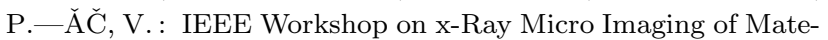
rials, Devices, and Organisms, Dresden, 2008, Book of abstracts.
[8] The European Standard EN 12543-5:1999, European Committee for Standardization, CEN, September. 1999.

[9] Miniature X-Ray Fast Digital Imager, User Manual, Photonic Science Ltd., February 2008.

10] HOLÝ, V.-PIETCH, U.-BAUMBACH, T.: High-Resolution X-Ray Scattering from Thin Films and Multilayers, Originally published as Volume 149 in the series: Springer Tracts in Modern Physics, 2nd ed., 2004, XVI, 408.

[11] SCHÄFERS, F.: RAY the BESSY ray-trace program, ver. 24.5.2008.

Received 30 June 2010

Zdenko Zápražný was born in 1980 and gained MSc in 2003 from Technological devices and systems, Faculty of Materials Science and Technology in Trnava, Slovak University of Technology. Since 2009 he is a PhD student at Institute of Electrical Engineering, SAS Piešt'any. His professional interests are mainly high resolution x-ray imaging technique.

Vladimír Áč, born 1943, MSc 1965, PhD 1979, Associate Professor 1994 from STU Bratislava, physics and electronics.

Dušan Korytár, born 1950, MSc 1973, PhD 1985, condensed matter physics.

František Dubecký, (Ing, CSc) was born in Bratislava, in 1946. He graduated at the Faculty of Electrical Engineering, Slovak University of Technology, in 1970. He received the PhD degree in Electronics and Vacuum Technology at the Institute of Electrical Engineering, Slovak Academy of Sciences (IEE SAS), in 1980. He is involved in the investigation of technology and performance of radiation detectors based on bulk GaAs and InP semiconductor compounds.

Zbigniew Stachura, Janusz Lekki, Jakub Bielicky, Ján Mudroň - biographical data not supplied.

\section{$* * *$}

This work was presented at 16-th International Conference Applied Physics of Condensed Matter, June 16-18, 2010, Malá Lučivná, Slovakia. 